\title{
Effect of the Standardized Management of Cancer Pain on Patients with Bone Metastasis of Lung Cancer in China
}

This article was published in the following Dove Press journal: Cancer Management and Research

\author{
Jing-Jing Jin ${ }^{\prime}$ \\ Tian-Tian $X u^{\prime}$ \\ Yan-Fang $\mathrm{Li}^{2}$ \\ Hong-Yang Wang' \\ Dan Zhang' \\ Pan-Pan Zhang' \\ $\mathrm{Li}$-Xin $\mathrm{Xu}{ }^{\prime}$ \\ Chun-Xiu Wang' \\ Zhu Fan' \\ Ling Wang' \\ Chen Liu' \\ Shuang Wang' \\ Hao-Tian Shi' \\ Cai-Hong $\mathrm{Li}^{1}$ \\ Hai-Fang Zhang' \\ Yan Huang'
}

'Department of Respiratory Medicine, North China University of Science and Technology Affiliated Hospital, Tangshan, Hebei 063000, People's Republic of China; ${ }^{2}$ Department of Pediatric Medicine, Hebei People's Hospital Affiliated to North China University of Science and Technology, Shijiazhuang, Hebei 050000, People's Republic of China

Correspondence: Yan Huang Department of Respiratory Medicine, North China University of Science and Technology Affiliated Hospital, No. 73 of Jianshe Road, Lubei District, Tangshan, Hebei 063000 , People's Republic of China Tel +86 I87I3877946

Email huangy9520I@I63.com
Objective: This study investigates the effect of the standardized management of cancer pain on patients with bone metastasis of lung cancer in China.

Patients and Methods: A total of 123 patients with bone metastasis of lung cancer were selected from the Respiratory Department of the Affiliated Hospital of North China University of Science and Technology. Among these patients, 62 patients who had not received standardized management of cancer pain from March 12, 2018, to September 11, 2018, were selected as the control group. In contrast, 61 patients who had received the standardized management of cancer pain from September 12, 2018, to March 11, 2019, were selected as the observation group. The former cohort accepted the conventional management of cancer pain, while the latter accepted the strict, standardized management of cancer pain. The demographic statistics, disease characteristics, and painkiller application of patients in these two groups were analyzed. Then, the analgesic effect and level of satisfaction were compared between these two groups.

Results: No significant differences were noticed between these two groups in terms of age, gender, smoking status, type of pathology, education level, previous treatment, and the Eastern Cooperative Oncology Group score, as well as other demographic and disease characteristics. As for the use of painkillers, opioid analgesics accounted for a higher proportion in the observation group than in the control group. Compared with the control group, pain improvement and patient satisfaction after analgesic treatment were significantly higher in the observation group ( $p<0.05)$.

Conclusion: The standardized management of cancer pain can considerably alleviate the pain of patients with bone metastasis of lung cancer and improve their quality of life. Furthermore, this type of management can increase satisfaction.

Keywords: standard management, lung cancer, cancer pain, bone metastasis, analgesic effect

\section{Introduction}

Pain is one of the common symptoms of cancer. Most cancer patients suffer from pain-induced physiological and psychological pressure. For cancer patients, pain creates the most unfavorable situation that reduces their quality of life and deprives them of their desire for life. Therefore, cancer pain has gradually attracted clinical attention. To illustrate the importance of pain, in 2002, the World Health Organization (WHO) listed pain as the fifth vital sign after the traditional four vital signs of respiration, blood pressure, body temperature, and pulse. ${ }^{1}$ However, scant attention has been paid to cancer pain mainly because of an inadequate 
understanding of the importance of pain, limited assessment of cancer pain, and incorrect treatment of pain, as confirmed by previous studies. ${ }^{2,3}$

More than half of cancer patients worldwide suffer from cancer pain. Breivik's ${ }^{4}$ and Hsieh's 5 investigations in Europe and Taiwan of China put the number of cancer pain patients between $50 \%$ and $70 \%$, with the therapeutic effect of cancer pain being dismal. The inadequate pain management of cancer patients prolongs the time of hospitalization, increases the cost of treatment, and aggravates doctor-patient relationships. To improve this situation, it is necessary to standardize the management of cancer pain. In 1986, WHO issued a set of guidelines on cancer pain control, $^{6-9}$ which improved pain management. However, the efforts were not sufficient and failed to deliver the desired results. This situation closely reflects China's national conditions. To standardize the pain management process, enhance standardized diagnosis and pain treatment, and improve patients' life quality, the Ministry of Health of China formulated the Cancer Pain Diagnosis Standards (2011 edition) in 2011. ${ }^{10}$ Despite some achievements, the results fell far short of the ideal.

In response to the Ministry of Health's initiative to establish a demonstration ward (painless ward) for the standardized treatment of pain, a demonstration hospital for the standardized treatment of pain was set up in the Department of Respiratory Medicine of the Affiliated Hospital of North China University of Science and Technology on September 12, 2018 to strengthen pain management, especially for patients with bone metastasis of lung cancer. This standardized management program succeeded in reducing cancer patients' pain. The following report presents the effect of this standardized management program.

\section{Patients and Methods}

This study was conducted in accordance with the declaration of Helsinki. This study was conducted with approval from the Ethics Committee of North China University of Science and Technology Affiliated Hospital. Written informed consent was obtained from the participants.

\section{Data}

A total of 123 patients suffering from pain with bone metastasis of lung cancer in the Affiliated Hospital of North China University of Science and Technology were selected for this study. Of this number, 66 patients were male, and 57 patients were female, aged between 42 and 81 years old, with an average age of $64.17 \pm 8.52$ years old. Among these patients, 62 patients who had been hospitalized in the Respiratory Department from March 12, 2018 to September 11, 2018 were assigned to the control group (before the setup of the demonstration hospital for the standardized treatment of cancer pain). In contrast, the remaining 61 patients who had been hospitalized in the demonstration hospital for the standardized treatment of cancer pain from September 12, 2018 to March 11, 2019 were assigned to the observation group.

\section{Methods}

A retrospective analysis was performed in this study. The 62 patients in the control group were empirically treated without following the standards of the three-step analgesic therapy. In contrast, the 61 patients in the observation group were treated strictly according to the standards of the three-step analgesic therapy; subsequently, they were timely evaluated. The specific treatment method was as follows. Patients in the experimental group were chosen according to the different levels of commonly used analgesics corresponding to the degree of pain. For mild pain, nonsteroidal anti-inflammatory drugs (NSAIDs) were used. If NSAIDs were ineffective for moderate pain, then moderate analgesic drugs such as buguizine hydrochloride tablets were used. For moderate and severe pain, adequate doses of opioids were considered. The experimental and control groups were only treated with oral analgesics, excluding the use of the patch, nerve block, palliative radiotherapy, and other treatments. The Numeric Pain Rating Scale (NPRS) was used to evaluate the patients' pain. This scale contained 11 points, ranging from 0 (painlessness) to 10 (severe pain). Each patient was given a corresponding oral painkiller, and the pain was re-evaluated after the drug took effect. The pain scores were compared between these two groups before and after the relevant treatment. The use of oral analgesic drugs in both groups was recorded. Furthermore, patients' satisfaction with analgesic treatment was also investigated.

\section{Observation Indicators}

Demographic and disease characteristics such as age, gender, smoking status, type of pathology, education level, previous treatment, and the Eastern Cooperative Oncology Group (ECOG) score were compared between the two groups. The application of oral painkillers was compared between the two groups. The pain scores were compared between the two groups before and after the standardized treatment. Satisfaction with the treatment of 
cancer pain was evaluated and compared between the two groups using the pain management satisfaction questionnaire designed by the experts of the department of oncology in our hospital. ${ }^{11,12}$ The evaluation standards were as follows: 75 points $<$ high satisfaction $\leq 100$ points; 25 points $<$ general satisfaction $\leq 75$ points; 0 points $<$ dissatisfaction $\leq 25$ points. The questionnaires were distributed by the researcher and completed by the patients after having received guidance. Total satisfaction percentage $=$ (number of high satisfaction + number of general satisfaction)/total number* $100 \%$.

The patients were followed up by telephone calls in the first, second, and fourth weeks after discharge to obtain information on their pain, medication, and adverse reactions.

\section{Statistical Processing}

SPSS 17.0 statistical software was used for data analysis. The Shapiro-Wilk test was used to analyze the normality of quantitative variables. Quantitative data consistent with the normal distribution are presented as mean \pm standard deviation $(\bar{x} \pm \mathrm{SD})$ and analyzed by the independent sample $t$-test. Qualitative data are presented in percentages $(\%)$. The difference was assessed by the chi-square test. $P<0.05$ was considered statistically significant.

\section{Results}

No statistically significant differences were found between the two groups in terms of demographic and disease characteristics, such as age, gender, smoking status, education level, ECOG score, type of pathology, and previous treatment $(p>0.05$, Table 1$)$.

The details of the application of oral analgesics in these two groups are presented in Table 2. In terms of painkiller use, the opioid analgesics in the observation group accounted for a higher proportion than the control group.

Table 3 displays the comparative pain scores between the two groups before and after treatment. Regardless of the type of group (i.e., control or observation), all pain scores show a significant decrease $(p<0.001)$. Compared with the control group, the decrease in the pain score was more obvious in the observation group.

Table 4 shows the comparative degrees of satisfaction with cancer pain treatment between the two groups. Compared with the control group, patients in the observation group had significantly higher satisfaction with cancer pain treatment $(p=0.002)$.

During the follow-up period, only a few patients had nausea, constipation, and other common adverse reactions;
Table I Demography and Disease Characteristics of Patients in the Two Groups

\begin{tabular}{|c|c|c|c|}
\hline Characteristics & $\begin{array}{l}\text { Control Group } \\
\text { [Case, (\%)] }\end{array}$ & $\begin{array}{l}\text { Observation Group } \\
\text { [Case, (\%)] }\end{array}$ & $P$ \\
\hline $\begin{array}{l}\text { Gender } \\
\text { Male } \\
\text { Female }\end{array}$ & $\begin{array}{l}35(56.45) \\
27(43.55)\end{array}$ & $\begin{array}{l}31(50.82) \\
30(49.18)\end{array}$ & 0.53 \\
\hline $\begin{array}{l}\text { Smoking history } \\
\text { Without } \\
\text { With }\end{array}$ & $\begin{array}{l}43(69.35) \\
19(30.65)\end{array}$ & $\begin{array}{l}46(75.41) \\
15(24.59)\end{array}$ & 0.45 \\
\hline Age & $63.7 I \pm 9.4 I$ & $64.64 \pm 7.56$ & 0.56 \\
\hline $\begin{array}{l}\text { ECOG score } \\
0 \\
1 \\
2\end{array}$ & $\begin{array}{l}37(59.68) \\
14(22.58) \\
11(17.74)\end{array}$ & $\begin{array}{l}35(57.38) \\
16(26.23) \\
10(16.39)\end{array}$ & 0.89 \\
\hline $\begin{array}{l}\text { The pathologic types } \\
\text { Adenocarcinoma } \\
\text { Squamous cell } \\
\text { carcinomas } \\
\text { Small cell lung } \\
\text { cancer }\end{array}$ & $\begin{array}{l}37(59.68) \\
12(19.35) \\
13(20.97)\end{array}$ & $\begin{array}{l}27(44.26) \\
10(16.39) \\
24(39.35)\end{array}$ & 0.08 \\
\hline $\begin{array}{l}\text { Level of education } \\
\text { Junior high and } \\
\text { below } \\
\text { High school } \\
\text { The university } \\
\text { Master or above }\end{array}$ & $\begin{array}{l}4(6.45) \\
24(38.71) \\
22(35.48) \\
12(19.36)\end{array}$ & $\begin{array}{l}2(3.28) \\
35(57.38) \\
14(22.95) \\
10(16.39)\end{array}$ & 0.19 \\
\hline $\begin{array}{l}\text { Treatment history } \\
\text { Without } \\
\text { With }\end{array}$ & $\begin{array}{l}28(45.16) \\
34(54.84)\end{array}$ & $\begin{array}{l}31(50.82) \\
30(49.18)\end{array}$ & 0.53 \\
\hline
\end{tabular}

no serious adverse reactions were reported. None of the patients showed any drug addiction.

\section{Discussion}

Most patients with bone metastasis of lung cancer in China suffer from pain and a poor quality of life. Some patients have even contemplated undesirable actions, such as suicide. Although the Cancer Pain Diagnosis Standards (2011 edition) were promulgated in China, limited progress was made in terms of alleviating cancer pain. Some Chinese scholars ${ }^{13-15}$ investigated the present situation of cancer pain management in China and discovered a huge gap between the control of patients' cancer pain and WHO's slogan of "Make Cancer Pain Patients Painless." Meanwhile, the global consumption of morphine is very low, which confirms that China has poor cancer pain control for the following reasons. First, the opium war caused patients to misunderstand painkillers, especially opioids, and pay excessive attention to side effects and 
Table 2 Application of Oral Analgesic in the Two Groups of Patients

\begin{tabular}{|l|l|l|}
\hline Painkiller Category & $\begin{array}{l}\text { Control Group } \\
\text { [Case, (\%)] }\end{array}$ & $\begin{array}{l}\text { Observation } \\
\text { Group [Case, (\%)] }\end{array}$ \\
\hline No painkiller & $6(9.68)$ & $1(1.64)$ \\
\hline NSAIDs & $13(20.97)$ & $7(11.47)$ \\
\hline Codeine phosphate tablet & $14(22.58)$ & $16(26.23)$ \\
\hline Buguizine hydrochloride tablet & $13(20.97)$ & $20(32.79)$ \\
\hline $\begin{array}{l}\text { Morphine sulfate sustained } \\
\text { release tablet }\end{array}$ & $8(12.90)$ & $11(18.03)$ \\
\hline $\begin{array}{l}\text { Oxycodone hydrochloride } \\
\text { sustained release tablet }\end{array}$ & $8(12.90)$ & $6(9.84)$ \\
\hline Summary & $62(100.00)$ & $61(100.00)$ \\
\hline
\end{tabular}

addiction. Second, patients in China have a high tolerance for pain; this means that they are reluctant to admit pain, resulting in minimal complaints. Third, patients have limited training on the standardized management of cancer pain. Finally, the wrong choice of painkiller undermines the effective management of cancer pain. ${ }^{16-21}$ To alleviate cancer patients' pain, it is necessary to establish a demonstration hospital for the standardized treatment of cancer pain, strengthen the management of cancer pain, train medical staff regularly, screen patients with bone metastasis of lung cancer after admission, and evaluate the dynamics of cancer pain. Furthermore, it is equally important to set up a propaganda and education system to enable patients and their families to effectively deal with cancer pain and use painkillers. It is also important to manage the use of anesthetic drugs in the cancer pain ward and use a double-lock management system to ensure the safe use of painkillers. It is also highly recommended to establish a follow-up system to analyze and evaluate the follow-up results, allowing for the adjustment of the analgesia plan when necessary. This standardized management of cancer pain can have a significant effect on patients who suffer from pain with bone metastasis of lung cancer in China. This study revealed that the demographic and disease characteristics such as age, gender, smoking status, education level, ECOG score, type of pathology, and previous treatment have no impact on the degree of pain in patients with bone metastasis of lung cancer. In terms of painkiller application in cancer pain patients, the proportion of opioid analgesics in the observation group was higher than that in the control group, with no serious adverse reactions and drug addiction. This finding indicates that the use of cancer pain drugs after the standardized management of cancer pain is highly effective. The pain score in these two groups declined after treatment, suggesting the significant alleviation of pain. Moreover, pain in Chinese patients with bone metastasis of lung cancer treated after the standardized management of cancer pain yielded significant improvement and high satisfaction for these patients $(p=0.002)$. The results of this study further affirm the value of the standardized management of cancer pain and encourage hospitals at all levels to continuously strengthen the management of cancer pain.

Table 3 Comparison of Pain Scores Between the Two Groups Before and After Treatment

\begin{tabular}{|c|c|c|c|c|c|c|}
\hline \multirow[t]{2}{*}{ Group } & \multirow{2}{*}{$\begin{array}{l}\text { The Number of } \\
\text { Cases }\end{array}$} & \multicolumn{2}{|l|}{ Pain Score } & \multirow{2}{*}{$\begin{array}{l}\text { The Correlation } \\
\text { Coefficient }\end{array}$} & \multirow[t]{2}{*}{$\mathbf{t}$} & \multirow[t]{2}{*}{$P$} \\
\hline & & $\begin{array}{l}\text { Before the } \\
\text { Treatment }\end{array}$ & $\begin{array}{l}\text { After the } \\
\text { Treatment }\end{array}$ & & & \\
\hline Control group & 62 & $6.15 \pm 1.68$ & $4.34 \pm 1.47$ & 0.53 & 9.27 & $<0.001$ \\
\hline $\begin{array}{l}\text { Observation } \\
\text { group }\end{array}$ & 61 & $6.02 \pm 1.51$ & $3.03 \pm 1.14$ & 0.63 & 19.58 & $<0.001$ \\
\hline
\end{tabular}

Table 4 Comparison of the Satisfaction with Cancer Pain Treatment Between the Two Groups

\begin{tabular}{|l|l|l|l|l|l|}
\hline Group & $\begin{array}{l}\text { The Number of } \\
\text { Cases }\end{array}$ & $\begin{array}{l}\text { Very Satisfied } \\
\text { [Case, (\%)] }\end{array}$ & $\begin{array}{l}\text { The General Satisfaction } \\
\text { [Case, (\%)] }\end{array}$ & $\begin{array}{l}\text { Not Satisfied with } \\
\text { [Case, (\%)] }\end{array}$ & $\begin{array}{l}\text { Satisfaction } \\
\text { (\%) }\end{array}$ \\
\hline $\begin{array}{l}\text { Control group } \\
\text { Observation group } \\
\chi 2\end{array}$ & 62 & $12(19.36)$ & $25(40.32)$ & $25(40.32)$ & 59.68 \\
$P$ & $21(34.43)$ & $32(52.46)$ & $8(13.11)$ & 86.89 \\
12.06 & & 0.002 \\
\hline
\end{tabular}


This research has some limitations. First, this was a retrospective and single-case study with a large sample size and, thus, possible risk of bias. Second, this study only included patients who had been admitted to the hospital, excluding outpatients. Future studies need to address these limitations to allow lung cancer patients with bone metastases in China to receive a more standardized and humanized management program aimed at alleviating their pain and improving their quality of life.

\section{Conclusion}

This study revealed that the standardized management of cancer pain for patients with bone metastasis of lung cancer can assist Chinese patients with the use of analgesics and the alleviation of cancer pain. Compared with conventional cancer pain treatment, the standardized management of cancer pain allows patients to feel more satisfied and enjoy an enhanced quality of life. This study proved the feasibility of the standardized management of cancer pain for cancer pain treatment.

\section{Funding}

This study was supported by "Lung cancer with metabolic syndrome management - Excellent Talents Project of Hebei Provincial Health Commission" and "Study on the relationship between detection of TKI resistance gene and non-small-cell Lung Carcinoma targeted therapy" (Item number:12140209A-23).

\section{Disclosure}

The authors declare no conflicts of interest.

\section{References}

1. Fan S, Peng L, Qi X. Analysis of the status quo of cancer pain control. Inform Chin Tradit Med. 2010;02:14.

2. Fisch MJ, Lee JW, Weiss M, et al. Prospective, observational study of pain and analgesic prescribing in medical oncology outpatients with breast, colorectal, lung, or prostate cancer. $J$ Clin Oncol. 2012;30:1980-1988. doi:10.1200/JCO.2011.39.2381

3. Breuer B, Fleishman SB, Cruciani RA, Portenoy RK. Medical oncologists' attitudes and practice in cancer pain management: a national survey. J Clin Oncol. 2011;29:4769-4775. doi:10.1200/JCO.2011.35.0561
4. Ferrell B, Whedon M, Rollins B. Pain and quality assessment/ improvement. J Nurs Care Qual. 1995;9:69-85. doi:10.1097/ 00001786-199504000-00010

5. Polomano RC, Dunwoody CJ, Krenzischek DA, Rathmell JP. Perspective on pain management in the 21st century. Pain Manag Nurs. 2008;9(1 Suppl):S3-10. doi:10.1016/j.pmn.2007.11.002

6. Colleau SM. Appraising the WHO analgesic ladder on its 20th anniversary. Cancer Pain Release. 2006;19:13.

7. American Cancer Society; National Comprehensive Cancer Network. Melanoma: treatment guidelines for patients (Part 1).. Dermatol Nurs. 2005;17(2):119-131.

8. Larue F, Colleau SM, Brasseur L, Cleeland CS. Multicentre study of cancer pain and its treatment in France. BMJ. 1995;310(6986):10341037. doi:10.1136/bmj.310.6986.1034

9. Scottish Intercollegiate Guidelines Network (SIGN). Control of Pain for Patients with Cancer. A National Clinical Guideline; 2000.

10. Ministry of Health of China. The department of the standardized pain treatment demonstration ward standards (2011 edition). Chin Clin Oncol. 2012;17(02):153-158.

11. Zhong H, Mo S. Application of standardized treatment for cancer pain in patients with pain resulting from lung cancer. Chin J Mod Drug Appl. 2019;13(20):16-17. doi:10.14164/j.cnki.cn11-5581/ r.2019.20.007

12. Zhong X, Li X, Lan M, Lin S. The application analysis of standard cancer pain nursing management measures in cancer pain patients. $J$ Tradit Chin Med Manage. 2018;26(06):48-50. doi:10.16690/j. cnki.1007-9203.2018.06.022

13. Yu ZW, Feng CL, Ning QY. Practice and experience of nurses in the establishment of demonstration ward for standardized treatment of cancer pain. Chin Med Guide. 2013;11:777-778. doi:10.15912/j.cnki. gocm.2013.16.155

14. Wang W, Cao B, Ning X, et al. Progress and challenge of cancer pain control in Beijing in 20 years - investigation of cancer pain status in Beijing multi-center (FENPAI4090). Chin J Pain Med. 2014;20(1):512. doi:10.3969/j.issn.1006-9852.2014.01.003

15. Huang Y, Zhang K, Wang J. Effect of standardized treatment technology popularization on treatment measures and efficacy in cancer pain patients in county. China Med Her. 2018;15(36):48-51.

16. Yu S, Wang XS, Cheng Y, Yang J, Cleeland CS. Special aspects of cancer pain management in a Chinese general hospital. Eur J Pain. 2001;5(Suppl):A:15-20. doi:10.1053/eujp.2001.0274

17. Li TD. Present implementation situation and prospects of cancer pain control strategy in China. J Qilu Oncol. 2003;01:1-5. doi:10.16073/j. cnki.cjcpt.2003.01.002

18. Wang XQ, Duan PB. The research progress of influencing factors of cancer pain control. J Nurs Admin. 2012;12:406-407. doi:10.3969/j. issn.1671-315X.2012.06.011

19. Yanjun S 1, Changli W, Ling W, et al. A survey on physician knowledge and attitudes towards clinical use of morphine for cancer pain treatment in China. Support Care Cancer. 2010;18(11):1455-1460. doi:10.1007/s00520-009-0768-2

20. Wang XS, Li TD, Yu SY, Gu WP, Xu GW. China: status of pain and palliative care. $J$ Pain Symptom Manage. 2002;24:177-179. doi:10.1016/S0885-3924(02)00435-9

21. Huang Y. Current status of pain management in China: an overview. Eur J Pain. 2001;5(Suppl):A:67-71. doi:10.1053/eujp.2001.0283
Cancer Management and Research

\section{Publish your work in this journal}

Cancer Management and Research is an international, peer-reviewed open access journal focusing on cancer research and the optimal use of preventative and integrated treatment interventions to achieve improved outcomes, enhanced survival and quality of life for the cancer patient.
The manuscript management system is completely online and includes a very quick and fair peer-review system, which is all easy to use. Visit http://www.dovepress.com/testimonials.php to read real quotes from published authors. 